\title{
Panorama Laboral de la Mujer en Colombia, una Mirada desde El Espinal-
}

\author{
Tolima
}

\section{Labour Panorama of women in Colombia, a look from El Espinal, Tolima}

\begin{abstract}
OMAR ERNESTO CASTRO GÜIZA
Abogado. Especialista en Derecho Laboral. Candidato a Magister en Derecho. Universidad Cooperativa de Colombia Sede Espinal

omar.castro@campusucc.edu.co
\end{abstract}

Lawyer. Specialist in labour law. Candidate to Master in Law. Universidad Cooperativa de Colombia Sede Espinal omar.castro@campusucc.edu.co

LUCAS CABALLERO MARTINEZ

Abogado Especialista en docencia universitaria. Universidad Cooperativa de Colombia Sede Espinal. lucas.caballero@campusucc.edu.co

Specialist lawyer in university teaching. Universidad Cooperativa de Colombia Sede Espinal. Lucas.caballero@campusucc.edu.co

Fecha de recepción: 12 de septiembre de 2011 Fecha de evaluación: 29 de noviembre de 2011 Fecha de aprobación: 30 de noviembre de 2011

RESUMEN. El análisis del trabajo desde la perspectiva de género obliga la observancia de los lineamientos del programa del trabajo decente propuesto por la OIT en pro de la erradicación de la discriminación, protección del derecho a la 
igualdad y la garantía a la igualdad de oportunidades para las mujeres trabajadoras. Es necesario examinar las políticas públicas y la normatividad nacional, así como las investigaciones adelantadas por académicos sobre el derecho del trabajo, con el ánimo de aportar elementos teóricos que permitan el análisis de la situación de la mujer trabajadora en Colombia para dar un panorama actual de sus condiciones laborales.

PALABRAS CLAVES: Derechos humanos, perspectiva de género, derecho a la igualdad, trabajo decente.

ABSTRACT. The analysis of the work from a gender perspective requires the observance of the guidelines of the decent work agenda proposed by the OIT in promoting the eradication of discrimination and protection of the right to equality and the guarantee of equal opportunities for women workers. It is necessary to examine public policies and national legislation, as well as the investigations conducted by academics on the law of the work, with the spirit to contribute theoretical elements that allow for the analysis of the current situation of the woman worker in Colombia to give a current view of their working conditions.

KEYWORDS: Human Rights, Gender Perspective, Right to equality, Decent work 


\section{Introducción}

Desde el comienzo de la humanidad la mujer ha contribuido positivamente con su trabajo al desarrollo de los pueblos, en virtud de aquel mandato bíblico: "comerás el pan con el sudor de tu rostro" (Nuestra Sagrada Biblia, 2010). Las condiciones laborales de aquel lejano ayer comenzando por el hombre prehistórico y sus innumerables estadios de cambio y desarrollo hasta hoy, la colocan en la cima de cada actividad que desempeña. Sin embargo, el papel de su trabajo depende de cada época, modalidad y lugar en que se ubique con sus múltiples variables, generadoras igualmente de problemas sociales y jurídicos, en los cuales brotan las reales condiciones que el estado y la sociedad les brinda en el mercado laboral (Engels, 1884).

Entre algunas de esas múltiples variables que han contribuido a la generación de problemas sociales y jurídicos en las políticas de género se encuentran: (i) la falta de coherencia entre los sexos en el mundo del trabajo; y, (ii) la globalización, definida por el Fondo Monetario Internacional como: "La globalización es una interdependencia económica creciente del conjunto de países del mundo, provocada por el aumento del volumen y la variedad de las transacciones transfronterizas de bienes y servicios, así como de los flujos internacionales de capitales, al tiempo que la difusión acelerada de generalidad de tecnología cuya incidencia en el campo laboral ha ocasionado su deterioro, generando altos índices de desocupados, y pocos empleos en condiciones inferiores a las mínimas 
legales, con una seguridad social deficiente, además de corrupta en todos sus niveles" (Fondo Monetario Internacional, 2006). Es por ello que las diferentes instituciones públicas y privadas de todos los países del mundo, deben reflexionar en este sentido brindando hoy tanto a hombres y mujeres en igualdad de condiciones un trabajo decente, entendido como la necesidad mas anhelada que deben compartir los individuos, las familias y la comunidad en toda sociedad, donde el estado es su garante.

A partir del objetivo general de este trabajo se hicieron dos planteamientos: uno, identificar desde una perspectiva de género las condiciones laborales de las mujeres trabajadoras, vistas desde la política de trabajo decente, propuesta por la OIT; (La OIT es la agencia que se ocupa de la problemática del empleo en Las Naciones Unidas, promoviendo la formación de normas internacionales de trabajo que fijen condiciones articuladas en materia de cumplimiento de los derechos laborales); y dos, determinar la existencia de las condiciones mínimas que permitan establecer su cumplimiento para el desarrollo del trabajo decente en Colombia.

Ahora bien, Pero ¿Qué es el trabajo decente presentado por primera vez en la ochenta y siete (87) reunión de junio de 1999 en Ginebra -Suiza- por la Conferencia Internacional del Trabajo? ¿Y cuáles son las condiciones laborales de 
las mujeres trabajadoras en general de todo el mundo de cara al trabajo decente? (Organizacion Internacional del Trabajo, 1999).

Para responder estas preguntas pilares de la temática en comento se debe partir de junio de 1999, cuando se llevó a cabo aquella reunión, tomándola en sentido retroactivo pero también hacia el futuro. Es necesario contar con la OIT proponente de este término, quien para desempeñar a cabalidad con su misión cuenta con tres órganos: El Consejo de Administración, La Oficina Internacional del Trabajo y La Conferencia Internacional del Trabajo, ésta última su motor deliberante y conformada por cuatro representantes de cada país miembro: dos en representación del gobierno y dos en representación de las asociaciones de patronos y de trabajadores (Campos Rivera, 2008, p. 72).

A través de las convenciones y de las recomendaciones internacionales del trabajo se concreta su actividad, orientada al mejoramiento de las condiciones de vida de los trabajadores, a la superación de las diferencias existentes entre el capital y el trabajo, sobre la base de la justicia y de la equidad, y al avance de la legislación laboral en el mundo, haciendo más productivos su esfuerzo, sin distingos de edad, sexo, estirpe o condición (Caldas, 1957, p. 80). 


\section{Marco histórico-social internacional de las mujeres trabajadoras y el trabajo decente}

El Chileno Juan Somavia en su primer informe como director general de la OIT en 1999, introdujo por primera vez el término trabajo decente como respuesta al deterioro de los derechos de los trabajadores que ocurrió mundialmente durante la década del 90; y como consecuencia del proceso de globalización y la necesidad de atender la dimensión de la misma. Luego, la primera noción que de trabajo decente se tenga hoy es esa: "Trabajo productivo en condiciones de libertad, equidad, seguridad y dignidad, en el cual los derechos son protegidos y que cuenta con remuneración adecuada y protección social". También es una reivindicación mundial con la que están comprometidos dirigentes políticos y las empresas públicas y privadas del mundo, caracterizado por cuatro objetivos: "derechos en el trabajo, oportunidades de empleo, protección social, y el dialogo social”, los cuales cumplen una función, como la inclusión social, erradicación de la pobreza, fortalecimiento de la democracia, desarrollo integral y la realización personal. (Organizacion Internacional del Trabajo, 1999, p. 41).

La Norteamericana Catharine Mackinnon utilizando el debate sobre marximismo y feminismo presenta un análisis sobre política, sexualidad y ley desde la perspectiva de las mujeres, basada en una teoría de género centrada en la subordinación sexual. Esta obra comienza con las respectivas afirmaciones del 
marxismo y del feminismo cuando analizan la desigualdad como tal; "reconstruye el feminismo en el campo epistemológico a través de la sexualidad como algo básico para la situación de la mujer y termina estudiando el poder institucional del Estado en el terreno más particular de la interpretación social de la mujer y el tratamiento que le da la ley. El resultado es una crítica bien fundamentada sobre la desigualdad y una visión transformada dirigida al cambio social" (Mackinnon, 1995, p. 43). Aunque no se relaciona esta obra directamente con el trabajo decente, nótese que cuatro años antes de aparecer este término ya se sentía en el mundo la desigualdad de género en el campo laboral.

Por otro lado, Gerry Rodgers, director del Departamento de investigación de políticas de la OIT trata acerca del papel que el paradigma del trabajo está llamado a desempeñar en la economía global. Agrega que la noción de "trabajo decente reúne al empleo, a los derechos laborales, a la seguridad y a la representación en una unidad con coherencia interna y que tiene sentido cuando se la considera en su totalidad". Insiste en este artículo promover el trabajo decente, es decir, la forma en que funciona la economía global, para que sus beneficios lleguen cada vez a más gente. El trabajo decente no es solo objetivo de desarrollo a nivel nacional, sino además un principio orientador para la economía mundial. Puntualiza diciendo que trabajo decente "es aquel que constituye un enfoque conjunto del trabajo, el empleo y el progreso social". (Rodgers, 2002, p. 13). 
Por su parte, Virgilio Levaggi, director adjunto de la Oficina Regional de la 0IT para América Latina y el Caribe, dice que trabajo decente

Es un concepto que busca expresar lo que debería ser, en el mundo globalizado, un buen trabajo o un empleo digno. El trabajo que dignifica y permite el desarrollo de las propias capacidades no es cualquier trabajo; no es decente el trabajo que se realiza sin respeto a los principios y derechos laborales fundamentales, ni el que no permite un ingreso justo y proporcional al esfuerzo realizado, sin discriminación de género o de cualquier otro tipo, ni el que se lleva a cabo sin protección social, ni aquel que excluye el dialogo social y el tripartismo (Levaggi, 2007, p. 6).

Del anterior concepto se concluye que no es lo mismo hablar de "trabajo decente" que de "un buen trabajo o empleo digno". El "trabajo decente" no excluye el empleo digno". Mejor dicho en términos precisos quien consigue un "Trabajo decente" tiene un empleo digno.

Respecto del programa de trabajo decente, la Chilena Malva Espinoza, identifica que el objetivo es sistematizar algunas de las nociones en las que se basa este concepto, el cual ha ido cogiendo cuerpo para transformarse hoy en uno de los objetivos estratégicos de la OIT. Surge como respuesta a la creciente desprotección de los trabajadores y de inseguridad en que se desenvuelven las 
sociedades contemporáneas del capitalismo globalizado. "Para que el trabajo decente sea relevante, debe sustentarse con datos de la realidad laboral de cada país". Lo define "Como un empleo de calidad que respete los derechos de los trabajadores en el cual se desarrollen formas de protección social”. Nótese que en relación a la primera definición se sustituye la idea de trabajo productivo por empleo de calidad; no aparece la referencia a los ingresos adecuados, tampoco el tripartismo y el dialogo social. (Espinoza, 2003, p. 61).

Siguiendo las estrategias de implementación y seguimiento al programa de trabajo decente, entre los días 18 y 20 de septiembre de 2007, se reunieron en Francia los países miembros de la OIT, y su conferencia central se denominó "El trabajo decente objetivo global y realidad nacional”, destacándose los siguientes temas: "Trabajo decente como objetivo global. Políticas, para un desarrollo sustentable"."Estándares internacionales para un trabajo decente, programas nacionales". "Organización Mundial de la Salud, Plan Global para la salud de los trabajadores"."Programas de trabajo decente en América Latina"."Promoviendo el trabajo decente en países de habla inglesa en África". "Estrategias para promover el trabajo decente en Brasil". Trabajo decente a nivel de las empresas en las industrias de logística y del transporte y en la cadena de suministro". "Cooperación multinacional para lograr un trabajo decente en los aeropuertos del mundo". Por lo que se puede observar el trabajo decente tiene mucha acogida (Organizacion Internacional del Trabajo, 2006, p.111). 
En el libro "trabajo decente para una mujer. Una propuesta de la OIT para acelerar la puesta en práctica de la plataforma de acción de Pekín", de septiembre de 2009, en uno de sus capítulos se refiere al "Genero, Formación y trabajo. La mujer en el mundo del trabajo: progresos y desfasajes. Un contexto cambiante". Se alude a que los procesos de mundialización, reestructuración económica y flexibilización de la producción han provocado cambios en las pautas de empleo, tornándose más inseguro e inestable para las mujeres en las últimas décadas. Los plazos y condiciones de participación de los hombres y mujeres en el mercado de trabajo se han redefinido con la flexibilidad en los procesos productivos y aumento de la demanda del trabajo femenino. Al respecto se indico, "La reforzada participación de la mujer en el empleo retribuido no se debe a factores y condicionamientos económicos, sino a cambios en su papel en la sociedad y prioridades en la vida según las tendencias de participación". Son más numerosas las mujeres educadas que alcanzan puestos de responsabilidad y crean sus propias empresas, lo cual hace más visible su contribución económica. Si se quiere mejorar su situación en el mundo del trabajo, se debe contar con: nexos entre la economía de asistencia y el trabajo; aquel que existe entre la economía estructurada y la informal; y, el de la calidad de empleo y protección social, principales retos de hoy. (Organizacion Internacional del Trabajo, 2009).

En el mismo sentido, en Reino Unido o la Gran Bretaña: (Inglaterra, Gales, Escocia e Irlanda de Norte), el informe de la Confederación Sindical Internacional, 
publicado con ocasión de su Primera Conferencia Mundial para la mujer de octubre de 2009, en Bruselas, Bélgica, la agenda para su conmemoración se tituló: "El Programa de Trabajo Decente: una perspectiva de género, vida decente para la mujer". Este informe fue preparado por Incomes Data Services asociado de investigación en El Reino Unido con sede en Londres. Por objetivo principal deben examinar las pruebas que existen en materia de trabajo decente para las mujeres trabajadoras; averiguar cómo se puede asegurar que un mayor número de mujeres tengan acceso a un trabajo decente; analizar la el salario, una medida fundamental de igualdad. La necesidad de este tipo de acción concluyó que "casi dos tercios de las mujeres del mundo en desarrollo ocupan puestos de trabajo vulnerables como trabajadoras por cuenta propia o en trabajos familiares no remunerados". (Naciones Unidas, 2009).

Es importante destacar respecto al tema, la 17ª reunión Regional Americana de la OIT celebrada entre el 14 y el 21 de diciembre de 2010 en Santiago de Chile , allí se definió la agenda hacia el trabajo decente en los siguientes términos: (i) "Representantes de gobiernos, trabajadores y empleadores de más de 30 países

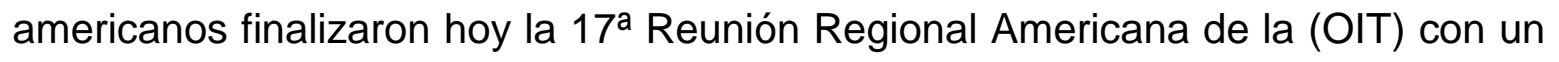
llamado a profundizar los esfuerzos para seguir avanzando en la senda del trabajo decente en el continente". (ii) "Los delegados destacaron la necesidad de avanzar por medio de un diálogo social más efectivo, de los temas como la creación de nuevas oportunidades de trabajo decente y productivo mediante la promoción y 
desarrollo de empresas sostenibles". La reunión contó con la presencia del Presidente de Chile, Sebastián Piñera, quien reafirmó la importancia del trabajo decente y la protección en el desarrollo económico y social de la región. El Vicepresidente de Colombia, Angelino Garzón, destacó el compromiso de su país con el trabajo decente (Reunion Regional Americana, 2010).

Otra de las referencias destacables en América Latina sobre estudios de género se plasmó en el 2006 en el libro "Trabajo decente y equidad de género en América Latina", en donde se refleja la importancia que tiene el trabajo decente desde que apareció en 1999 hasta hoy. Este libro es el resultado del trabajo de un gran número de personas cuyos aportes han permitido profundizar en los análisis relativos a la situación de las mujeres trabajadoras y a la promoción de la igualdad de género en América Latina en el contexto de la Agenda de Trabajo Decente. Refleja algunos de los principales resultados del trabajo que fue realizado entre enero de 1999 a abril de 2005. "Es necesario considerar también que en América Latina las desigualdades y la discriminación de género guardan una importante interrelación con las desigualdades y la discriminación étnico-racial. En consecuencia, las mujeres indígenas y afrodescendientes experimentan una situación de doble desventaja" (Abramo, 2006).

En el mismo sentido, se expidió por parte de la confederación internacional de sindicatos informe denominado: "Las mujeres siguen sin tener las mismas 
oportunidades laborales que los hombres" en el trabajo decente. Esto advierte precisamente: que las mujeres siguen sin tener las mismas oportunidades de empleo que los hombres. (Bruno Perinelli, 2010).

Por su parte, en estudios realizados para el centenario de Argentina y Chile, Ana López Dietz presentó el trabajo: "Feminismo y emancipación en el ideario de las mujeres trabajadoras de Argentina y Chile". El objetivo de este trabajo es estudiar el nacimiento y la formación de las organizaciones de mujeres trabajadoras y la prensa obrera femenina a inicios del siglo XX en Argentina y Chile, indicando cómo se articula la relación entre las temáticas de género y clase. Los Códigos Civiles manifestaban la autoridad del hombre sobre la mujer y los hijos, arrogando el derecho a los varones de administrar los bienes e incluso fijar el domicilio familiar. La mujer no podía representarse así misma ante la ley, ni ejercer profesión sin autorización del marido. No había reconocimiento de derechos sexuales ni reproductivos para las mujeres. Para ingresar al mercado laboral debe realizar trabajos que se relacionan con lo que se considera debe ser una mujer, escalando el mundo político, cultural y social feminista, frente a los hombres, lo que hoy está bien visto desde el Estado, la Iglesia, la elite y los hombres trabajadores,...". (Dietz, 2010).

Reiterativo de la discriminación laboral de género la OIT mediante comunicado de prensa llamado "Más mujeres eligen trabajar, pero la igualdad de género en el 
trabajo aún está muy lejos", hace ver que aún existe un escollo entre hombres y mujeres en las oportunidades de trabajo y calidad de empleo. Empero, según Jane Hodgee, Directora de la Oficina para la Igualdad de Género de la OIT, se hará un esfuerzo para que hombres y mujeres puedan participar de manera libre y activa, en su emancipación a "través del desarrollo de la capacidad empresarial, abordar la desigualdad de salarios aumentar la protección social "y fortalecer la participación de las mujeres en el diálogo social" (Organizacion Internacional del Trabajo, 2010).

\section{Situacion laboral de la mujer en Colombia: marco superior, legal, jurisprudencial y doctrinario}

En cuanto a las normas jurídicas que regulan las actividades y otorgan derechos a las mujeres Colombianas en su calidad de trabajadoras, es necesario indicar que son múltiples y codifican diversos aspectos, por ello se hace indispensable estructurar las mismas desde los principios constitucionales que luego se desarrollarán por las leyes y demás normas internas sobre la materia.

En primer lugar, se encuentra que la mujer como integrante de la familia y en muchos casos como cabeza de la misma, se protege desde el artículo $5^{\circ}$ constitucional al reconocer a la familia como la institución básica de la sociedad. Así mismo, en el artículo 13 la norma primaria señala que todas las personas 
nacen libres e iguales ante la ley, y no hay lugar a discriminación alguna, de lo cual se colige que las mujeres deben gozar de los mismos derechos y oportunidades que los hombres. En cuanto al derecho fundamental del trabajo, el articulo 25 ibíd indica que este "Es un derecho y una obligación social y goza, en todas sus modalidades, de la especial protección del Estado. Toda persona tiene derecho a un trabajo en condiciones dignas y justas." En el artículo 43 de la norma precitada se observan principios destinados específicamente a proteger a la mujer, destacándose la especial asistencia que debe recibir durante el embarazo y después del parto, así como el trato singular que debe recibir en el caso de ser cabeza de familia. Referente a la protección social el artículo 48 constitucional expresa en uno de sus apartes que "Se garantiza a todos los habitantes el derecho irrenunciable a la Seguridad Social." Por otro lado, el artículo 53 contentivo de los principios mínimos fundamentales en el derecho del trabajo señala entre otros la protección especial a la mujer y a la maternidad. (Asamblea nacional constituyente, 1991).

En relación con el desarrollo de los principios constitucionales que protegen a la mujer trabajadora en Colombia se observa un amplio marco legal regulatorio que se tratara a continuación.

En primera medida, se referencian las leyes alusivas a la mujer trabajadora del sector oficial. Así como lo señala el profesor López Fajardo, los artículos $3^{\circ}$ de la 
ley 53 de 1938 y $2^{\circ}$ de la ley 197 del mismo año reconocieron el amparo a la maternidad para las servidoras públicas, expresando que la mujer que sea despedida sin justa causa dentro del periodo de embarazo o dentro de los tres meses posteriores al parto, tendría derecho a los salarios correspondientes a noventa días, sin perjuicio de las indemnizaciones a que haya lugar. (Fajardo, 2010). Sin embargo a partir del artículo 34 de la ley 50 de 1990 modificatorio del artículo 236 del código sustantivo del trabajo toda mujer trabajadora del sector público o privado en estado de embarazo tendrá derecho a una licencia de 12 semanas en la época del parto remuneradas con el salario que devengue al entrar a disfrutar del descanso, la cual será cubierta hoy por el sistema general de seguridad social en salud (Congreso de Colombia, 1991). Empero, si la trabajadora embarazada es mayor de quince años y menor de dieciocho años, la jornada laboral no podrá exceder de cuatro horas diarias a partir del séptimo mes de gestación y durante la lactancia, sin disminución de su salario y prestaciones sociales, según lo prescribe el artículo 116 de la ley 1098 de 2006 (Congreso de Colombia, 2006). Por su parte el artículo 166 de la ley 100 de 1993 ofrece una especial protección a la mujer embarazada indicando sobre el tema de la atención materno infantil que el plan obligatorio de salud para las mujeres en estado de embarazo cubrirá los servicios de salud en el control prenatal, la atención del parto, el control del postparto y la atención de las afecciones relacionadas directamente con la lactancia. El Plan Obligatorio de Salud para los menores de un año cubrirá la educación, información y fomento de la salud, el fomento de la 
lactancia materna, la vigilancia del crecimiento y desarrollo, la prevención de la enfermedad, incluyendo inmunizaciones, la atención ambulatoria, hospitalaria y de urgencias, incluidos los medicamentos esenciales; y la rehabilitación cuando hubiere lugar, de conformidad con lo previsto en la mencionada ley y sus reglamentos. Además del Plan Obligatorio de Salud, las mujeres en estado de embarazo y las madres de los niños menores de un año del régimen subsidiado recibirán un subsidio alimentario en la forma como lo determinen los planes y programas del Instituto Colombiano de Bienestar Familiar y con cargo a éste (Congreso de Colombia, 1993).

Retomando el código sustantivo del trabajo (Decreto 2663 de 1950), el artículo 237 señala que la trabajadora que sufra en el embarazo de un aborto o un parto prematuro no viable tiene derecho a una licencia remunerada de dos a cuatro semanas. En el mismo sentido el artículo 238 del precitado código reza "El empleador está en la obligación de conceder a la trabajadora dos descansos, de treinta (30) minutos cada uno, dentro de la jornada para amamantar a su hijo, sin descuento alguno en el salario por dicho concepto, durante los primeros seis (6) meses de edad."

Así mismo los artículos 239, 240 y 241 expresan que ninguna trabajadora puede ser despedida por motivos de embarazo o lactancia y en el caso de que ocurra, este será nulo, obligándose al empleador a conservar el puesto de trabajo. Por su 
parte el artículo 242 indica que las mujeres no pueden desempeñar labores peligrosas, insalubres o que requieren grandes esfuerzos. En lo concerniente al reglamento interno de trabajo de las empresas, el artículo 108 del código en sus numerales 13 y 14 señalan que deben incluir las labores que no deben ejercitar las mujeres, con el ánimo de conseguir mayor higiene, regularidad y seguridad en el trabajo (Congreso de Colombia, 1951). Como reiteración y ampliación de esta protección se expidió la ley 1468 de 2011 "por la cual se modifican los artículos 236, 239, 57,58 del código sustantivo del trabajo y se dictan otras disposiciones", que amplía el termino de la licencia de maternidad a 14 semanas, además de reiterar la prohibición del despido de la mujer en estado de embarazo o dentro del término de la licencia, entre otros temas tratados por dicha norma como desarrollo del principio constitucional protector de la mujer en calidad de trabajadora y que merece una protección especial desde el derecho del trabajo. (Congreso de la republica, 2011).

En lo que corresponde a la ley 1257 de 2008 "Por la cual se dictan normas de sensibilización, prevención y sanción de formas de violencia y discriminación contra las mujeres, se reforman los Códigos Penal, de Procedimiento Penal, la Ley 294 de 1996 y se dictan otras disposiciones", se observa que esta tiene como objeto la adopción de normas que permitan garantizar para todas las mujeres una vida libre de violencia, tanto en el ámbito público como en el privado, el ejercicio de los derechos reconocidos en el ordenamiento jurídico interno e internacional, el 
acceso a los procedimientos administrativos y judiciales para su protección y atención, y la adopción de las políticas públicas necesarias para su realización. En cuanto al tema laboral el artículo 12 de la misma norma reza "Medidas en el ámbito laboral. El Ministerio de la Protección Social, además de las señaladas en otras leyes, tendrá las siguientes funciones:

1. Promoverá el reconocimiento social y económico del trabajo de las mujeres e implementará mecanismos para hacer efectivo el derecho a la igualdad salarial.

2. Desarrollará campañas para erradicar todo acto de discriminación y violencia contra las mujeres en el ámbito laboral.

3. Promoverá el ingreso de las mujeres a espacios productivos no tradicionales para las mujeres.

Parágrafo. Las Administradoras de Riesgos Profesionales (ARP), los empleadores y/o contratantes, en lo concerniente a cada uno de ellos, adoptarán procedimientos adecuados y efectivos para:

1. Hacer efectivo el derecho a la igualdad salarial de las mujeres.

2. Tramitar las quejas de acoso sexual y de otras formas de violencia contra la mujer contempladas en esta ley. Estas normas se aplicarán también a las cooperativas de trabajo asociado y a las demás organizaciones que tengan un objeto similar. 
3. El Ministerio de la Protección Social velará porque las Administradoras de Riesgos Profesionales (ARP) y las Juntas Directivas de las Empresas den cumplimiento a lo dispuesto en este parágrafo (Congreso de Colombia, 2008).

Por su parte, en el sector público se expidió La ley 581 del 31 de mayo de 2000, por la cual se reglamenta la adecuada y efectiva participación de la mujer en los niveles decisorios de las diferentes ramas y órganos del poder público, de conformidad con los artículos 13, 40, 43 y 115 de la Carta Política. De la lectura de sus 17 artículos se concluye que: (i) la mujer tiene un papel muy importante en la vida del estado a nivel nacional, departamental y municipal, en las superintendencias, los establecimientos públicos y las empresas industriales o comerciales del estado, ora como presidenta, ya como gobernadora o bien como alcaldesa municipal; (ii) que se consagran dos niveles: el máximo nivel decisorio que son los de mayor jerarquía en las entidades en las tres ramas y órganos del poder público en los niveles nacional, departamental, regional, provincial, distrital y municipal; $y$, otros niveles decisorios que son cargos de libre nombramiento y remoción de la rama ejecutiva, del personal administrativo de la rama legislativa y de los demás órganos del poder público; (iii) que la participación adecuada de la mujer se hará efectivo aplicando por parte de las autoridades nominadoras mínimo el treinta por ciento de los cargos de tales niveles, si esto no se cumple se sancionará con suspensión del cargo y destitución del mismo por segunda vez; (iv) que en los casos de nombramiento por ternas en ella debe ir el nombre de una 
mujer, y si es por el sistema de listas se incluirán hombres y mujeres en igual proporción, lo mismo cuando se trata su participación en los procesos de selección; y, (v) que el estado promocionará la participación de la mujer en el sector privado al mercado laboral, así como educación y capacitación especializada en igualdad de sexos. De lo comentado hasta aquí se puede observar que esta ley protege a la mujer en todos sus aspectos, colocándola casi en igualdad de condiciones a los hombres en la ley del trabajo. (Congreso de Colombia, 2000).

En cuanto, al sistema de seguridad social en pensiones el parágrafo 4 del artículo 33 de la ley 100 de 1993 otorga a la madre trabajadora que tenga hijo que padezca de invalidez física o mental debidamente calificada, y que dependa económicamente de la madre, el acceso a la pensión de vejez solo cumpliendo con el requisito de cotización mínima de semanas exigidas en el régimen de prima media con prestación definida para obtener tal derecho.

Po otro lado, y teniendo en cuenta que el trabajo es protegido desde todas su modalidades, han aparecido algunas normas que protegen situaciones especiales de la mujer, un ejemplo de ello es la ley 1232 de 2008 "Por la cual se modifica la Ley 82 de 1993, Ley Mujer Cabeza de Familia y se dictan otras disposiciones." que expresa entre otros aspectos que la mujer cabeza de familia requiere de especial protección, y que el gobierno nacional debe promover el fortalecimiento 
de sus derechos económicos, sociales y culturales, además debe incrementar el acceso a trabajos dignos y estables (Congreso de Colombia, 2008).

En lo referido al fomento del empleo aparece la Ley de formalización y generación de empleo (Congreso de Colombia, 2010), cuyos ejes centrales son la simplificación de trámites y los descuentos tributarios y parafiscalaes para empresas que inicien su actividad económica después de su entrada en vigencia; todo ello en aras de incentivar la creación de nuevos empleos para "jóvenes menores de 28 años y mujeres mayores de 40 años que hayan estado sin contrato de trabajo durante los últimos 12 meses". Además de lo anterior, agrega otros incentivos como la simplificación de trámites laborales y comerciales, modificando el Código sustantivo del trabajo en lo que tiene que ver con el reglamento interno de trabajo, los descuentos salariales, tramite de préstamos y la compensación en dinero de las vacaciones (Legis, 2011).

En cuanto a la interpretacion jurisprudencial, las altas cortes colombianas han tenido una intensa actividad que se ha refelejado en sus diversos pronunciamientos, de los cuales citamos los de mayor relevancia a continuacion.

En el año de 1997 la corte constitucional emite el fallo C-470 (sentencia hito reconceptualizadora) en virtud de demanda de constitucionalidad del artículo 239 del código sustantivo del trabajo y con ponencia del Dr. Alejandro Martínez 
Caballero, la corte reconceptualiza su tesis sobre la el derecho a la estabilidad laboral reforzada de la mujer embarazada, indicando que aunque el tema ya había sido tratado en anteriores sentencias tales como la C-710 de 1996, es necesario unificar criterios acerca de los derechos de las trabajadoras embarazadas, e indica que no solo procede la indemnización especial por despido en estado de embarazo prevista en el ordenamiento laboral, sino que además si se comprueba que no hubo justa causa para el mismo, se entenderá que el despido de la mujer embarazada trabajadora es ineficaz y se entenderá que entre las partes sigue operando la relación laboral con todos sus deberes y derechos.

Esta nueva doctrina constitucional sobre el despido del trabajo de una mujer trabajadora embarazada amplia sus efectos también a las mujeres que laboren como servidores públicas, y con los mismos derechos de las del sector privado.

La Corte Constitucional en Sentencia T-420 de mayo 25/2010, (Yerly Enciso vs Representaciones olas decorativas, 2010) se refiere a la protección constitucional especial que se le debe brindar a la mujer trabajadora embarazada, y a su estabilidad laboral, ya que dicha protección no opera de forma automática, sino que previamente se deben cumplir estos requisitos: que el despido se produzca durante el fuero de maternidad; que a la fecha del despido el empleador conocía el embarazo; que no medie autorización competente para el despido; y, que amenace el mínimo vital de la madre y del hijo por nacer. La presunción por 
embarazo corresponde al empleador, y su justificación debe estar consagrada en las causales de despido con justa causa. Ello no lo excluye a que tenga conocimiento de su gravidez, sino ampliar su protección y evitar que si no hay justa causa para el despido, aquel alegue que nunca supo del embarazo, y ante la falta de pruebas que demuestren lo contrario se niegue dicho amparo .

Sentencia C-101 de 2007. "Discriminación en razón del género". M.P. Alfredo Beltrán Sierra. Allí se hacen planteamientos discriminatorios de la mujer en leyes, como su sometimiento a la voluntad del hombre en el ámbito familiar, cultural, social y el derecho; así los reflejan las leyes de la discriminación histórica de la mujer, entre ellas las siguientes: 8aㅡ de 1922 se les permitió ser testigos; 28/1932 confirió a las casadas capacidad civil plena; en la Constitución del 86 solo los colombianos varones mayores de 21 años eras ciudadanos; la reforma constitucional del 45 les otorgó la ciudadanía de manera restringida; el Acto Legislativo 03 de 1954 les confirió el derecho al voto; por el Plebiscito del $1^{\circ}$ de diciembre de 1957, adquirieron las mayores de 21 años el derecho a elegir y ser elegidas; el Decreto 2820/74 eliminó las desigualdades entre el hombre y mujeres en el matrimonio; la Constitución del 91 consagró la igualdad total entre hombres y mujeres en la Administración Pública"; y, la ley 581/00 reglamentó "la adecuada y efectiva participación de la mujer en los niveles decisorios de las diferentes ramas y órganos del poder público". Agregó la Corte que existen otras normas que consagraban conductas discriminatorias que constituían una vulneración del 
derecho a la igualdad, como: la que consagró una causal de nulidad del matrimonio sólo respecto de la mujer; la que le negó el acceso a la única escuela de cadetes del país. Siguiendo esta línea jurisprudencial declaró la inconstitucionalidad parcial de los artículos 1852 del Código Civil y 906, numeral 1 del Código de Comercio que establecían la nulidad del contrato de venta entre cónyuges no divorciados. Conclúyese de lo anterior que las "diferencias en el trato, lejos de ser razonables y proporcionadas, perpetúan estereotipos culturales y, en general, una idea vitanda y contraria a la Constitución, de que la mujer es inferior al hombre".

"Una buena inspección es requisito ineludible para disminuir el déficit de trabajo decente". (Entrevista al Presidente Sala Laboral Corte Suprema de Justicia, Carlos Ernesto Molina) en la cual el jurista se refirió a las debilidades que el país y la Rama Judicial deben superar sobre el trabajo decente, que aún está en construcción desde que la OIT lo propuso en 1999 como meta que debía lograrse en todas las circunstancias de la vida globalizada. Hoy ese trabajo decente debe ser la aspiración por un trabajo productivo, en condiciones de libertad, equidad, seguridad y dignidad para todo tipo de trabajo legítimo, sea o no subordinado. Los empleadores pueden promocionar el trabajo decente ofreciendo a hombres y mujeres un trato digno no discriminatorio; y no incurriendo en esquemas de tercerización como el mal uso de cooperativas de trabajo asociado, o el trabajo en 
misión. Todo esto se logra si hay un eficiente control por parte del estado (Molina, 2011).

Respecto de la garantia de los derechos laborales en las cooperativas de trabajo asociado, la corte constitucional Sentencia T-550 de 2004, dice que hay que encontrar argumentos constitucionales "para apretarle la disciplina a estos engendros de intermediación laboral"; que es innegable la ilegalidad con que actúan; que "su mantenimiento riñe con la existencia del "trabajo decente" en el país decente al que aspiran todos los colombianos",son fuente de injusticias que atentan contra el trabajo decente de las mujeres trabajadoras; Asimismo plantea Carlos Cadavid que en la Sentencia T-873/05 la corte constitucional dice que si existe relación entre cooperados y cooperativas mediante contratos cooperativos, ello no excluye la existencia de una verdadera relación laboral (Cadavid, 2010) .

La jurisprudencia de la Corte Constitucional frente a la creación del trabajo decente, hace las siguientes reflexiones: desde 1991 se puso de presente el giro que se le dio a la concepción jurídica del trabajo; lo caraterizó como uno de los derechos sociales y económicos, los cuales deben interpretarse en estrecha relación con los principios de igualdad, libertad y dignidad humana; es garantía de las condiciones mínimas de subsistencia como medio para la atención del mínimo vital; se le concibe como un presupuesto de la realización y autonomía personal por cuanto responde a la necesidad del ser humano de sentirse útil; el Estado 
tiene que ver con la garantía de las condiciones que posibilitan que las personas tengan un empleo; eso implica permitir a las personas acceder al empleo o conservar el que ya tienen; el Estado en relación con la cuestión laboral tiene que ver con la garantía del trabajo en condiciones de dignidad; La OIT para englobar todas estas nociones propuso el concepto de trabajo decente, cuyo objetivo es "promover oportunidades para que hombres y mujeres accedan a un trabajo decente y productivo en condiciones de libertad, equidad, seguridad y dignidad humana"; para dicha Organización ese concepto se orienta hacia sus cuatro objetivos estratégicos: la promoción de los derechos laborales; la promoción del empleo; c) la protección social contra las situaciones de vulnerabilidad, y, d) el fomento del diálogo social". Por lo tanto el objetivo del Estado es garantizar para todos un trabajo decente en condiciones dignias. (Corte constitucional, 1999).

En la Sentencia C-101 de 2007. "Discriminación en razón del género". M.P. Alfredo Beltrán Sierra la corte constitucional hace un estudio sobre planteamientos discriminatorios de la mujer en leyes, como su sometimiento a la voluntad del hombre en el ámbito familiar, cultural, social y el derecho; así los reflejan las leyes de la discriminación histórica de la mujer, entre ellas las siguientes: $8^{\text {a }}$ de 1922 se les permitió ser testigos; 28/1932 confirió a las casadas capacidad civil plena; en la Constitución del 86 solo los colombianos varones mayores de 21 años eras ciudadanos; la reforma constitucional del 45 les otorgó la ciudadanía de manera restringida; el Acto Legislativo 03 de 1954 les confirió el 
derecho al voto; por el Plebiscito del $1^{\circ}$ de diciembre de 1957, adquirieron las mayores de 21 años el derecho a elegir y ser elegidas; el Decreto 2820/74 eliminó las desigualdades entre el hombre y mujeres en el matrimonio; la Constitución del 91 consagró la igualdad total entre hombres y mujeres en la Administración Pública"; y, la ley 581/00 reglamentó "la adecuada y efectiva participación de la mujer en los niveles decisorios de las diferentes ramas y órganos del poder público". Agregó la Corte que existen otras normas que consagraban conductas discriminatorias que constituían una vulneración del derecho a la igualdad, como: la que consagró una causal de nulidad del matrimonio sólo respecto de la mujer; la que le negó el acceso a la única escuela de cadetes del país. Siguiendo esta línea jurisprudencial declaró la inconstitucionalidad parcial de los artículos 1852 del Código Civil y 906, numeral 1 del Código de Comercio que establecían la nulidad del contrato de venta entre cónyuges no divorciados. Conclúyese de lo anterior que las "diferencias en el trato, lejos de ser razonables y proporcionadas, perpetúan estereotipos culturales y, en general, una idea vitanda y contraria a la Constitución, de que la mujer es inferior al hombre".

El Consejo de Estado tratando el tema de la reforma política a las elecciones locales que se realizarán el 30 de octubre de 2011 indico que el iniciso $3^{\circ}$ del artìculo 107 de la Carta Política fue modificlado por el Acto Legislativo 01 de julio 14 de 2009 y quedó así: "Los Partidos y Movimientos Políticos se organizarán democráticamente y tendrán entre algunos de sus principios rectores la equidadad 
de género,. (Congreso de Colombia, 2009)." El artículo 28 de La Ley 1475 de 2011 sobre la equidad de género e inscripción de candidatos preceptuó: "Las listas donde se elijan 5 o mas curules para corporaciones de elección popular o las que se sometan a consulta deberán conformarse por mínimo un $30 \%$ de uno de los géneros" (Congreso de colombia, 2011). Para el Consejo de Estado, Sala de Consulta y Servicio Civil, Consejero Ponente: Enrique José Arboleda Perdomo, el 27 de julio de 2011 en aras de dar aplicación al criterio de equidad e igualdad de género, al consultársele por parte del Ministro del Interior y de Justicia, si las listas de candidatos inscritas antes de entrar en vigencia la ley 1475 , deben adaptarse a su artículo 28 "sobre el porcentaje mínimo de participación femenina en los procesos de elección popular o corporaciones públicas ", respondió: "Si, las listas que a la fecha de entrada en vigencia de la ley 1475 de 2011, se encuentran inscritas y no cumplen la proporción de género, deben ser modificadas para cumplir con el principio de equidad de género vigente desde el Acto Legislativo 01 de 2009". (Consejo de Estado, 2011).

Por su parte, la doctrina nacional ha sentado posicion desde varios puntos de vista que aquí trataremos de manera suscinta: Respecto de los derechos de la mujer, se publico un documento por parte de la Oficina en Colombia del alto comisionado de las Naciones Unidas para los derechos humanos, la cual trabaja sobre el Convenio celebrado el 29 de noviembre de 1996 entre el Gobierno Colombiano y las Naciones Unidas. Se indica que la diferencia se origina en la 
violencia y discriminación contra la mujer, cuyos antecedentes vienen de un sistema ancestral de jerarquías entre los géneros; desconociendo principios de igualdad, seguridad, libertad, integridad y dignidad. La comunidad internacional se ha comprometido a hacer efectiva la plena participación de la mujer en igualdad de condiciones que los hombres. La Oficina quiere concientizar al Estado Colombiano en la comprensión y difusión de sus derechos según estos puntos: "Preguntas y respuestas sobre los derechos de la mujer e Instrumentos Internacionales de protección de los derechos de la mujer". Las condiciones jurídicas y sociales de la mujer son en igualdad de ambos sexos, eliminando todas las formas de discriminación contra la mujer, ratificadas e incorporadas en la legistlación internna por la ley 04 de 1981 y reglamentada por el Decreto 139 de 1990. En conclusión: la mujer tiene derecho a vivir en un sistema social sin discriminación de género; a una vida libre; a ser valorada y educada; a contribuir en el desarrollo y bienestar de la sociedad; así como a la reproducción y protección de la maternidad. (Naciones Unidas, 2002).

En el mismo sentido el Informe de equidad salarial y condiciones laborales de las mujeres en Colombia, según la Internacional de Servicios Públicos ISP, para lo cual (La ISP es una Federación Sindical a nivel mundial, no gubernamental, que representa 20 millones de mujeres y hombres empleados en entidades públicas 0 afiliados a organizaciones sindicales de 155 países del mundo) las mujeres constituyen una parte creciente de la fuerza de trabajo remunerada, es decir, el 
$65 \%$ de los afiliados de los sindicatos pertenecientes a la ISP. Desde el Congreso de 2002 se adoptó el principio de igualdad de género entre hombres mujeres por cuanto la equidad de remuneración es un derecho fundamental. "La equidad de remuneración significa remuneración justa por el trabajo que se realiza y comprende: igual remuneración por trabajo equiparable con empleos idénticos", con todos los factores salariales. Se logra cuando el trabajo hecho por mujeres se paga en pie de igualdad con el de los hombres, y su diferencia se debe a que es subvalorado. La segregación de la mujer en todos los sectores de la economía cuando mas predomina la mujer en determinado oficio, mas baja es la remunecación; y si mayor es el predominio masculino, mas alta es aquella. Basta con ver el censo del Ministerio de la Protección Social de 2005 hacia atrás, para concluir que con la aplicación de la flexibilidad laboral disminuyó el número y la tasa de sindicalización. El trabajo decente para las mujeres sin discriminación en el último trimestre de 2006, de acuerdo con las estadísticas de dicho Ministerio y el Dane, la tasa de ocupación de los hombres en el País fue del 64.9\%, y la de las mujeres del $37.4 \%$. La tasa del desempleo para las mujeres fue del $14.9 \%$ y para las mujeres del $8.9 \%$. Considérase que debe llevarse estudio de casos que evaluen los empleos y los salalrios devengados, sus causas y hallar soluciones que superen la brecha salarial de género. (Denisse Moreno Sierra, 2008)

En la publicación "Género y Justicia", se encuentra: (i) el módulo "Género y Justicia" de Magdala Velásquez Toro, coautoría de Paola Salgado Piedrahita y 
Manuel Ricardo Toro; y, (ii) el acuerdo 4552/08 “Justicia, Derecho y Género" del Consejo Superior de la Judicatura: aquél se refiere al principio de igualdad y no discriminación para los servidores judiciales, a los derechos humanos de las mujeres, a la categoría de género y su aplicación judicial (Consejo superior de la judicatura, 2008). Como antecedentes cita la discriminación de las mujeres "en las fuentes históricas de la normatividad colombiana"; la jurisprudencia de la Corte Constitucional con casos como los concursos de mérito. El acuerdo 4552/08 invoca la Carta de 1991, las leyes 270/96, 581/00, 823/03 y 1009/06 y la "Convención para la eliminación de todas las formas de discriminación contra la mujer", vigente desde febrero 19 de 1982 (Magdala Velásquez, 2009).

\section{Datos estadísticos importantes}

Es pertinente y necesario resaltar algunos datos estadísticos provenientes del Departamento Administrativo Nacional de Estadística (DANE) y cuyo punto de partida es el gran censo de 2005 en donde se puede distinguir varios aspectos que reflejan la situación socioeconómica, familiar, educacional y laboral entre otras de las mujeres en Colombia. En los aspectos laborales se identificaron y observaron varios aspectos tales como, actividad productiva, edades de las trabajadoras, ingresos promedios, afiliación a seguridad social y otras (Departamento Nacional de Estadistica, 2005). Estos datos han sido actualizados trimestralmente, por lo cual se toma como punto de referencia el informe vigente 
que data del trimestre móvil de Mercado laboral Enero-Marzo 2011 que indica que del total nacional de la población colombiana (44’540 mil personas) el 50,7\% son mujeres (22'570.mil) de ellas el 51,1\% (17’926 mil) están en edad para trabajar, y el 42.0\% (9’205 mil) pueden ser económicamente activas, pero solo el 39.9\% (7’655 mil) de las mujeres están ocupadas, además se distingue una tasa de desempleo femenino del $16.8 \%$ frente a un $9.2 \%$ en los hombres, aunado a que la principal posición ocupacional fue la de trabajo por cuenta propia con un $42.6 \%$. (Departamento Nacional de Estadistica, 2005).

Ahora bien, en el departamento del Tolima los últimos datos referenciados son los de 2010, los cuales indican que en el departamento hay 1'387.641 habitantes, de los cuales 697.426 son hombres y 690.215 son mujeres, en este mismo año se presentó una tasa global de participación de $67,0 \%$, una tasa de ocupación de $57,2 \%$ y una tasa de desempleo de $14,6 \%$ (DANE, 2010). En lo que corresponde al municipio de El Espinal la población total en 2010 fue de 76.378 habitantes de los cuales 38.540 son hombres y 37.832 mujeres, distinguiendo que el $78 \%$ del total de la población está en edad para trabajar y que existe un $54.60 \%$ de tasa de ocupación (Alcaldia municipal El Espinal-Tolima, 2011). Así mismo se distingue en el municipio que el $58,6 \%$ de la población ocupada está en la informalidad de los cuales el $62,8 \%$ son mujeres y el $37,2 \%$ son hombres (Alcaldia municipal de El Espinal, 2011) de lo cual se colige que estos trabajadores están totalmente desprotegidos respecto a beneficios laborales se refiere. 
Al observar los múltiples datos estadísticos se infiere que en Colombia, la mujer supera en número a los hombres, situación de la cual no se aparta el departamento del Tolima, ni menos el Espinal, pero llama la atención que hay mayor ocupabilidad laboral masculina, sin embargo tratándose de trabajadores informales superan en número las mujeres, dato este relevante toda vez que las condiciones laborales de las personas que ejercen esta modalidad de trabajo son precarias e insuficientes para garantizar su vida digna.

Al poner de presente estas alarmantes cifras se indago sobre las políticas públicas de empleo para el departamento del Tolima y para el municipio de El Espinal sin encontrar datos muy alentadores, sin embargo hay algunos estudios cuyo objeto es la formulación de soluciones en el tema laboral para el Tolima, destacándose el estudio que está en desarrollo y es liderado por la gobernación del Tolima en convenio con la universidad del Tolima y que tiene como objetivo principal el de "Hacer del Tolima una región ganadora dando solución a los problemas de la gente, buscando una mayor competitividad y desarrollo mediante un crecimiento sostenido de la economía, la integración y adecuación del territorio, que permitan una disminución del Desempleo, garantizando a los ciudadanos sus derechos constitucionales, propendiendo por su inclusión social, haciendo que el ciudadano del Tolima recupere la confianza en las acciones del Gobierno y como objetivos específicos: los de reactivar el crecimiento de la economía del Departamento generando empleo y ocupación y disminuir el índice de desempleo del Tolima y 
de Ibagué buscando que sea similar al de la Nación." (Gobernacion del TolimaUniversidad del Tolima, 2011).

\section{Metodología:}

La investigación aquí expuesta es de tipo descriptivo y explicativo así como exponen los metodólogos (Hernandez, Fernandez, \& Baptista, 2003) los cuales indican que" los estudios descriptivos se centran en recolectar datos que muestran un evento, una comunidad, un fenómeno, hecho, contexto o situación". En razón a ello esta investigación analiza la implementación del programa del trabajo decente propuesto por la Organización Internacional del Trabajo como estrategia de obligatorio cumplimiento para el estado colombiano en su calidad de miembro de este organismo internacional. Se inicia con referentes internacionales europeos, de América latina, para luego revisar la evolución histórica del trabajo de la mujer en Colombia, hasta llegar a la actualidad. Así mismo se observan las políticas públicas y los instrumentos jurídicos internacionales y nacionales utilizados para la implementación y aplicación del programa de OIT ya mencionado, en busca de la eliminación de la discriminación y la desigualdad de las mujeres en cuanto al trabajo se refiere.

Desde un estudio exploratorio cualitativo y cuantitativo, se hace un análisis histórico, teórico y estadístico con datos provenientes de los principales organismos internacionales y nacionales que fungen como autoridades en 
políticas públicas protectoras de los derechos de los trabajadores, así como de los estudios adelantados por algunos académicos y los pronunciamientos de las altas cortes colombianas que permiten dar un panorama de la situación actual del acceso de la mujer al trabajo formal en Colombia, el aumento de la informalidad y las garantías laborales existentes para la aplicación del programa del trabajo decente.

\section{Conclusiones}

De la visión global del sendero recorrido hasta aquí, brota una serie de datos que permiten concluir en forma categórica las mejores condiciones de las políticas de género del mundo femenino, con fundamento en la globalización y en la noción que de trabajo decente se tiene hoy desde sus orígenes en junio de 1999, en la ochenta y siete (87) reunión de la OIT en Ginebra Suiza con su máximo exponete el Chileno Juan Somavia. Para su estudio se le dividió: a) en una parte introductoria en la cual el estado del arte aflora con un interrogante sin respuesta: ¿Qué hay?; y, b) en dos grandes vertientes cada una apuntando al mismo objetivo, pero perfectamente diferenciables entre sí: la primera encasillando su

marco histórico-social; y, la segunda el marco superior, legal, jurisprudencial y doctrinario ya observadas cada una en el cuerpo del escrito presente. 
Por ultimo, "el trabajo decente es un concepto preliminar y provisional en construcción, de carácter integrativo y de profundo contenido ético, en cuya realización es necesario combinar aspectos relativos a los derechos laborales, el empleo, la protección y el dialogo con un todo integrado, que constituye una meta, un marco para la definición y actuación de políticas, un método de organización de actividades y programas, y una plataforma para la asociación con otras entidades". (Memorias del director Juan Somavia, 89 reunión, conferencia internacional, 1999, OIT) Sus características son: trabajo productivo y seguro, con ingresos adecuados, con protección social y diálogo social, libertad sindical, negociación colectiva y participativa. Sin equívocos puédese afirmar que: el progreso es el signo del trabajo decente, y con empleo digno lo reclama la gente.

\section{Referencias}

Abramo, L. (2006). Trabajo decente y equidad de genero en America Latina. Santiago de Chile: Oficina Internacional del Trabajo.

Alcaldia municipal de El Espinal. (2011). Oficio N.080 ssm. El Espinal-Tolima.

Alcaldia municipal El Espinal-Tolima. (2011). Oficio N.0606. El Espinal-Tolima. 
Asamblea nacional constituyente. (1991). Constitucion politica de Colombia. Bogota: Leyer.

Bruno Perinelli. (2010). Las Mujeres siguen sin tener las mismas oportunidades laborales que los hombres en trabajo decente. Confederacion Internacional de Sindicatos.

Cadavid, C. A. (2010). Zigzag jurisprudencial frente a los abusos de las cooperativas de trabajo asociado. Renovacion Sindical , 1-4.

Caldas, T. L. (1957). Comentario al Regimen Laboral Colombiano. Bogotá: Legis.

Campos Rivera, D. (2008). Derecho Laboral Colombiano ( $9^{\circ}$ ed.). Santa Fé de Bogota: Temis.

Congreso de Colombia. (14 de Julio de 2009). Diario oficial 47.410 .

Congreso de Colombia. (7 de Junio de 1951). Codigo sustantivo del trabajo. Diario oficial 27622.

Congreso de Colombia. (23 de Diciembre de 1993). Ley 100. Diario oficial 41148. 
Congreso de Colombia. (8 de Noviembre de 2006). ley 1098. Diario oficial 44446 .

Congreso de Colombia. (17 de Julio de 2008). ley 1232. Diario oficial 47.053 .

Congreso de Colombia. (4 de Diciembre de 2008). Ley 1257. Diario oficial 47.193 .

Congreso de Colombia. (29 de Diciembre de 2010). Ley 1429. Diario oficial 47.937

Congreso de colombia. (14 de Julio de 2011). Ley 1475. Diario oficial 48.130 .

Congreso de Colombia. (1 de enero de 1991). ley 50. Diario Oficial 39.618.

Congreso de Colombia. (31 de Mayo de 2000). Ley 581. Diario oficial 44.026 .

Congreso de la republica. (30 de Junio de 2011). ley 1468. Diario oficial 48.116 .

Consejo de Estado. (2011). CONCEPTO. Bogotá.

Consejo susperior de la judicatura. (2008). Acuerdo 4552. Bogota: Sala adminsitrativa.

Corte constitucional. (1999). Jurisprudencia al dia. Bogotá. 
DANE. (2010). Principales indicadores del mercado laboral. Tolima.

Denisse Moreno Sierra, I. R. (2008). Informe de equidad salarial y condiciones laborales de las mujeres en Colombia. Bogotá: Compes Impresores.

Departamento Nacional de Estadistica. (2005). Gran encuesta de hogares.

Dietz, A. L. (2010). Feminismo y Emancipacion en el ideario de las mujerees trabajadoras. Procesos historicos , 24-37.

Engels, F. (1884). El Origen de la Familia, La Propiedad Privad y El Estado. Zurich-Suiza.

Espinoza, M. (2003). Trabajo Decente y Protecion social. Santiago de Chile: Oficina Internacional del trabajo.

Fajardo, A. L. (2010). Elementos de derecho del trabajo. Bogota: El profesional Itda.

Fondo Monetario Internacional. (2006). Informe Anual. Washington: Fondo Monetario Internacional. 
Gobernacion del Tolima- Universidad del Tolima. (2011). Formulacion de una politica publica para generacion de empleo en condiciones dignas para el departamento del Tolima. Ibague, Tolima, Colombia.

Hernandez, R., Fernandez, C., \& Baptista, P. (2003). Metodologia de la Investigacion. Mexico: MacGraw-Hill.

Legis. (15 de Abril de 2011). Ley 1429 de formalizacion y generacion de empleo. Ambito Juridico, pág. 3.

Levaggi, V. (2007). ¿Que es el trabajo decente? Peripecias , 46, 1-4.

Mackinnon, C. A. (1995). Hacia una Teoria Feminista del Estado. Madrid: Catedra.

Magdala Velasquez, P. S. (2009). Genero y justicia. Bogotá: Escuela judicial.

Molina, C. E. (2011). Una buena inspección es requisito ineludible para disminuir el déficit de trabajo decente. Actualidad Laboral y Seguridad Social .

Naciones Unidas. (2009). El Programa del Trabajo Decente: Una perspectiva de Genero, vida decente para la mujer. Bruselas. 
Naciones Unidas, A. c. (2002). Derechos de la mujer. Bogotá: Nuevas ediciones Itda.

Nuestra Sagrada Biblia. (2010). Bogota: San Pablo.

Organizacion Internacional del Trabajo. (2006). Conferencia Internacional. Dusserdolrf: OIT.

Organizacion Internacional del Trabajo. (2010). Más mujeres eligen trabajar, pero la igualdad de género en el trabajo aún está muy lejos. Ginebra: Oficina Internacional del Trabajo.

Organizacion Internacional del Trabajo. (1999). reunion 87. Ginebra.

Organizacion Internacional del Trabajo. (2009). Trabajo Decente para una Mujer. Pekin: O.I.T.

Reunion Regional Americana. (2010). Decada del Trabajo Decente en las Ameicas. Santiago de Chile: Organizacion Internacional DeL Trabajo.

Rodgers, G. (2002). El Trabajo Decente como una Meta para la Economia Global. Bolentin Cinterfor , 9-28. 
Yerly Enciso vs Representaciones olas decorativas, t-2526601 (Corte Constitucional 25 de Mayo de 2010).

\section{Jurisprudencia}

Colombia, Corte Constitucional (1997), sentencia C-470, M.P. Alejandro Martínez Caballero

Colombia, Corte Constitucional (2010), sentencia T-420, M.P. María Victoria Calle Correa

Colombia, Corte Constitucional (2007), sentencia C-101, M.P. Rodrigo Escobar Gil

Colombia, Corte Constitucional (2004), sentencia T-550, M.P. Manuel José Cepeda

Colombia, Corte Constitucional (2004), sentencia T-873, M.P. Manuel José Cepeda. 